\title{
Survey of Absorbed Dose from Chest X-Ray of Paediatric Patients in Port Harcourt, Nigeria: A Cross-Sectional Study
}

\author{
Zedekiah Uriah Emmanuel $^{1}$, Michael Promise Ogolodom², \\ Awajimjana Nathaniel Mbaba $^{3}$, Hyacienth Uche Chiegwu', \\ Victor Kelechi Nwodo², Daniel Chimuanya Ugwuanyi², Nengi Alazigh ${ }^{3}$, \\ Efe Omita ${ }^{4}$
}

${ }^{1}$ Department of Physics Rivers State University, Nkpolu-Oroworukwo P.M.B 5080, Port Harcourt. Rivers state, Nigeria.

${ }^{2}$ Department of Radiography and Radiological Sciences, Nnamdi Azikiwe University Anambra State, Nigeria ${ }^{3}$ Radiology Department Rivers State University Teaching Hospital, Port Harcourt, Nigeria.

${ }^{4}$ Department of Physics, Federal University of Technology, Owerri, Imo State, Nigeria.

\begin{abstract}
Background: Radiation protection in paediatric radiology deserves special attention as children are supposed to be more sensitive to radiation than adults.

Aim: This study was designed to evaluate the radiation doses for paediatric patients undergoing diagnostic chest X-ray examination.

Materials and Methods: This was a crosssectional survey, which targeted paediatric patients of (0-10) years who were referred by their physicians for chest X-rays examination. The data used for this work were generated using a Thermoluminescence dosimeter (TLD) chip. One TLD chips was placed in the front of the chest to measure the Entrance Surface Dose (ESD) $(\mu \mathrm{Gy})$ and another at the back of the patient directly opposite the one in front to measure the Exit Dose (ED) ( $\mu \mathrm{Gy}$ ). Patient dose, age, ESD, ED and absorbed dose were obtained. The obtained data were analyzed using descriptive statistics.
\end{abstract}

Results: The mean ESD, ED and absorbed dose values were $1.8330 \pm 1.122 \mathrm{mGy}, 1.0913 \pm$ $0.7505 \mathrm{mGy}$ and $0.7520 \pm 3.8160 \mathrm{mGy}$ respectively. The ED values in chest $\mathrm{X}$-rays were $0.73 \pm 0.30 \mathrm{mGy}$ for age group <1 year, $1.15 \pm 0.91 \mathrm{mGy}$ for age group $1-5$ years and 610 years $1.09 \pm 0.75 \mathrm{mGy}$. The ESD were $3.06 \pm$ $1.76 \mathrm{mGy}$ for age group $<1,3.02 \pm 2.04 \mathrm{mGy}$ for

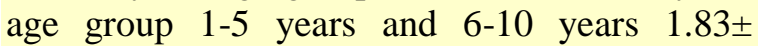

$1.12 \mathrm{mGy}$. The absorbed dose values obtained were $1.88 \pm 1.75 \mathrm{mGy}$ for age group <1 year, $1.88 \pm 1.67 \mathrm{mGy}$ for age group $1-5$ years and $0.75 \pm 3.82 \mathrm{mGy}$ for age group 6-10 year.

Conclusion: The values for Exit Dose, Entrance Surface Doses, and Absorbed Dose have been determined and it was found to be slightly higher than UNSCEAR values.

Keywords: Children, Diagnostic reference level, Radiation

\section{INTRODUCTION}

The chests X-ray is the most common radiological investigation and is frequently carried out to evaluate paediatric conditions such as asthma, pneumonia, congenital heart disease, persistent cough etc. Children receive overdose of radiation as a result of radiographic procedures, which is necessitated by the small body size of paediatric population and they are particularly susceptible to certain forms of radiation induced cancer, particularly leukemia. A diagnostic reference level (DRL) is advisory, and in practice is set so that if the value is exceeded regularly, the practice involved should be investigated ${ }^{[1]}$.

Knowledge and correct use of appropriate radiographic exposure factors 
e.g nominal focal spot size, filtration, focus to image plane distance and tube voltage is necessary because these have a considerable impact on image quality, and thus may have implications on dose. Permanent parameters of apparatus such as total tube filtration and anti-scatter grid characteristics should also be taken into consideration. ${ }^{[2]}$

The main concern for adverse health effects from radiation exposure in paediatric imaging is related to the increase risk of cancer incidence and mortality. ${ }^{[3]}$ Radiation protection in paediatric radiology deserves special attention as children exposed to radiation at an age below 5years are 2-to-3 fold more sensitive when compared with adults. ${ }^{[4]}$ Elawed ${ }^{[5]}$, is of the opinion that in carrying out paediatric X-ray examinations, there should be justification for the investigation so as to optimized radiation dose to the patient.

In view of this, while the optimization principle should be applied to all examinations of paediatrics patients, priority should be given to those examinations that deliver high doses. The decision as to, which dose quantity is most suitable should be made according to the availability of the required measurement equipment and DRL values. This study is aimed to evaluate the radiation doses for paediatric patients undergoing diagnostic chest X-ray examination in a Diagnostic centre in Port Harcourt.

\section{MATERIAL AND METHODS}

A cross-sectional survey design was adopted for this study, which was carried out in a single Diagnostic Center in Port Harcourt, Rivers State, Nigeria among paediatric patients of (0-10) years of age, who were referred by their physicians for chest X-rays examination. A simple random sampling method was used to select the study sample size in line with the set inclusion criteria. The ethical approval (UPTH/ADM/90/S.II/ VOL.XL/449) for this study was obtained from the Research and Ethics committee of University of Port Harcourt Teaching Hospital, Rivers State,
Nigeria after adequate evaluation of the study protocol. Informed consent from parents was obtained for free access to some vital patient's information like folders, request forms and radiological reports for screening and for enrolment into the study from 14th July 2017 to September 31 2017.

\section{Instrument and methods of data collection}

The equipment used in this study include; three phase X-ray generator, a thermoluminescent Dosimeters (TLD) made of Lithium Fluoride (LiF) that is (832 TLD) chips with X-ray absorption properties close to the human tissue and deeper traps ensures negligible fading and long term dose storage with sensitivity of $(10 \mu \mathrm{Gy}-100 \mu \mathrm{Gy})$, and Harshaw TLD Reader.

The X-ray examinations were performed using the GE MAX 4 Plus portable GE X-ray machine(GE MAX 4 plus:2169360-6) kilovoltage: $40-100 \mathrm{kVp}$ and inherent filtration of $2.0 \mathrm{~mm}$ aluminium equivalent and setting such as $\mathrm{KVp}$ and $\mathrm{mAs}$ values for each examination was selected from the control panel the machine.

Entrance Skin Dose of 40 paediatric patients has been considered in this study. After obtaining consent from the patient's parent. Also the radiographers were also informed on how to place the dosimeters on the child. The TLD pellets used in this study were of volume small enough to minimize the effects on the back scatter factor ${ }^{[6]}$. One TLD chips was placed in the front of the chest as to measure the entrance surface dose (ESD) ( $\mu \mathrm{Gy}$ ) and another at the back of the patient directly opposite the one in front to measure the exit dose (ED) ( $\mu \mathrm{Gy}$ ). Care was taken to ensure that the paediatric patients were comfortable during the examination. The following parameters were recorded: patient dose, age, ESD, ED, and absorbed dose were obtained respectively. These TLD chips were later sent to Centre for Energy Research and Training Ahmadu Bello University, Zaria. By using Thermo scientific ${ }^{\mathrm{Tm}}$ HARSHAW 
$\mathrm{TLD}^{\mathrm{Tm}}$ model 3500 manual reader provides manual readout of TL chips.

\section{Statistical Analysis}

The obtained data were analyzed using statistical package for social science (SPSS) version 20 and the results were presented in table and charts. Descriptive statistics (mean, standard deviation and standard errors) was used for statistical analysis and the variables obtained were compared with the recommended standard values. The Exit Dose values in chest $\mathrm{X}$ rays of paediatric patients are $0.73 \pm$ $0.30 \mathrm{mGy}$ for age group <1 year, $1.15 \pm$ $0.91 \mathrm{mGy}$ for age group 1-5 years and 6-10 years $1.09 \pm 0.75 \mathrm{mGy}$ while the Exit Dose (ED) from UNSCEAR for < 1 year = $0.02 \mathrm{mGy}, 1-5$ years $=0.03 \mathrm{mGy}$ and $6-10$ years $0.04 \mathrm{mGy}$. The Entrance Surface Dose from UNCEAR. ${ }^{[3]}$ For $<1$ year $=0.02 \mathrm{mGy}$, $1-5$ years $=0.03 \mathrm{mGy}$ and $6-10$ years $=$ $0.04 \mathrm{mGy}$. The average normal absorbed dose to the chest in a chest X-ray for paediatric patients from child dose programme of National Radiological
Protection (NRPB)-SR270 is $0.02 \mathrm{mGy}$ Hart, et al. ${ }^{[7]}$

\section{RESULTS}

Out of 40 participants, the majority $55 \%(\mathrm{~N}=22)$ were within the age group of 610 years with mean ESD, ED and Absorbed dose values of $1.8330 \pm 1.122 \mathrm{mGy}, 1.0913 \pm$ $0.7505 \mathrm{mGy}$ and $0.7520 \pm 3.8160 \mathrm{mGy}$ respectively (Table 1). The Entrance Surface Dose (ESD) obtained in our study are; $3.06 \pm 1.76 \mathrm{mGy}$ for age group $<1$, $3.02 \pm 2.04 \mathrm{mGy}$ for age group 1-5 years and $6-10$ years $1.83 \pm 1.12 \mathrm{mGy}$ (Figure 2 ). The absorbed doses obtained in our study across the studied age groups were age group $<1$ year $=1.88 \pm 1.75 \mathrm{mGy}$, for age group $1-5$ years is $1.88 \pm 1.67 \mathrm{mGy}$ and $6-10$ year is $0.75 \pm 3.82 \mathrm{mGy}$ while (Figure 3). In Comparing the Entrance Surface Dose (ESD) and Exit Dose (ED) from figure 4, we have: for < 1 year age group: 3.06 \pm $1.76 \mathrm{mGy}$ and $0.73 \pm 0.30 \mathrm{mGy}$, for $1-5$ years age group is $3.02 \pm 2.04 \mathrm{mGy}$ and $1.5 \pm$ $0.91 \mathrm{mGy}$, for $6-10$ years age group is $1.83 \pm$ $1.12 \mathrm{mGy}$ and $1.09 \pm 0.75 \mathrm{mGy}$ respectively (Figure 4).

\begin{tabular}{|l|l|l|l|l|l|}
\multicolumn{7}{c}{ Table 1: Descriptive Statistical Analysis } \\
\hline \multirow{3}{*}{ ESD IN } & YEARS & N & MEAN & STD. DEVIATION & STD. ERROR \\
& $<1$ & 9 & 3.0589 & 1.76328 & .58776 \\
& $1-5$ & 9 & 3.0178 & 2.04450 & .68150 \\
& $6-10$ & 22 & 1.8330 & 1.12155 & .23386 \\
\hline \multirow{3}{*}{ ED OUT } & $<1$ & 9 & 7311 & 30209 & .10070 \\
& $1-5$ & 9 & 1.1522 & .90869 & .30290 \\
& $6-10$ & 22 & 1.0913 & .75048 & .15649 \\
\hline \multirow{3}{*}{ ABSORBED } & $<1$ & 9 & 1.8822 & 1.75412 & .58471 \\
& $1-5$ & 9 & 1.8800 & 1.66725 & .58946 \\
& $6-10$ & 22 & .7520 & 3.81600 & .17015 \\
\hline
\end{tabular}

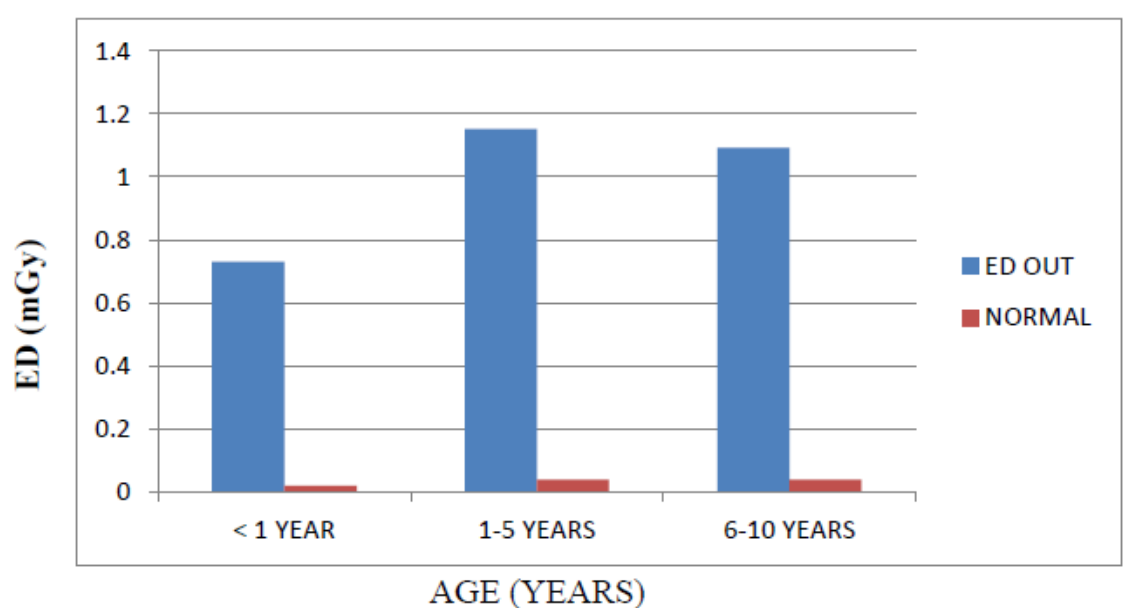

Figure 1. Measured Exit Doses compared with the normal values 
Zedekiah Uriah Emmanuel et.al. Survey of absorbed dose from chest $x$-ray of paediatric patients in Port Harcourt, Nigeria: a cross-sectional study.

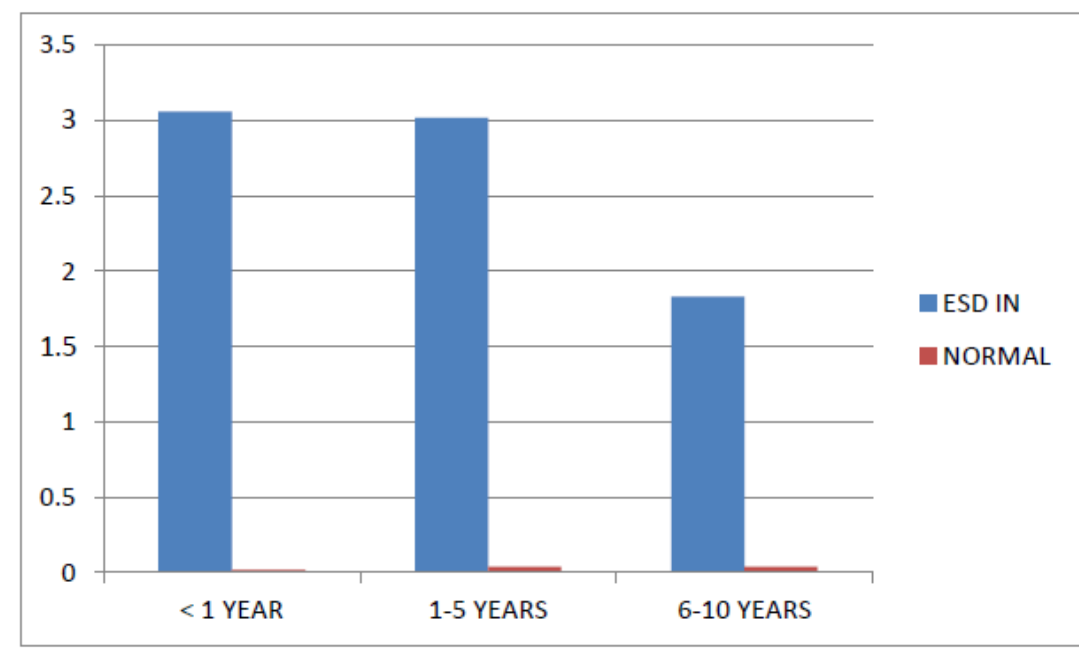

Figure 2. Measured entrance surface Dose (ESD) compared to Normal values of ESD

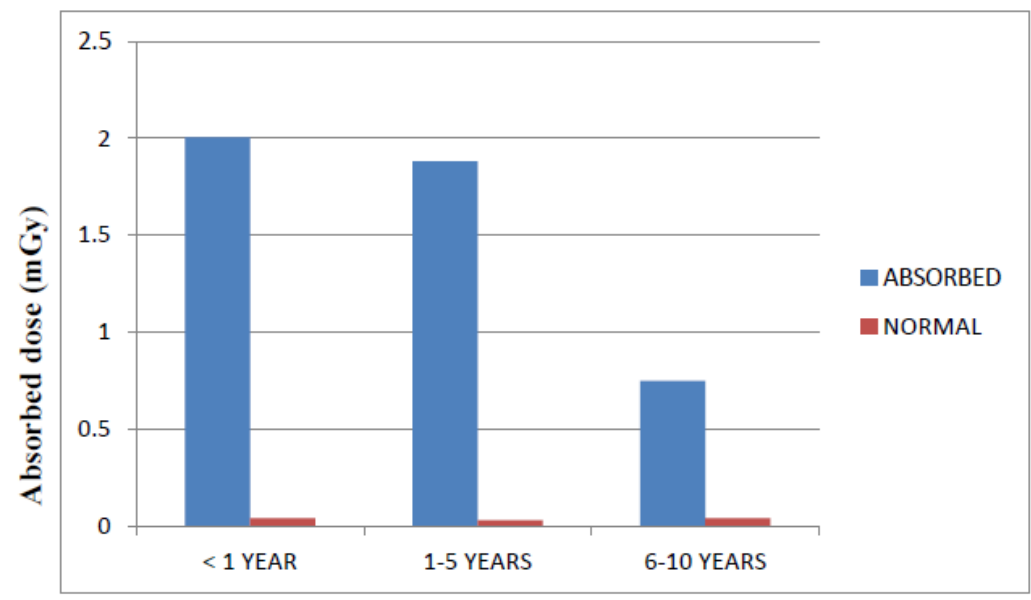

AGE (YEARS)

Figure 3. Measured Absorbed Doses compared to Normal.

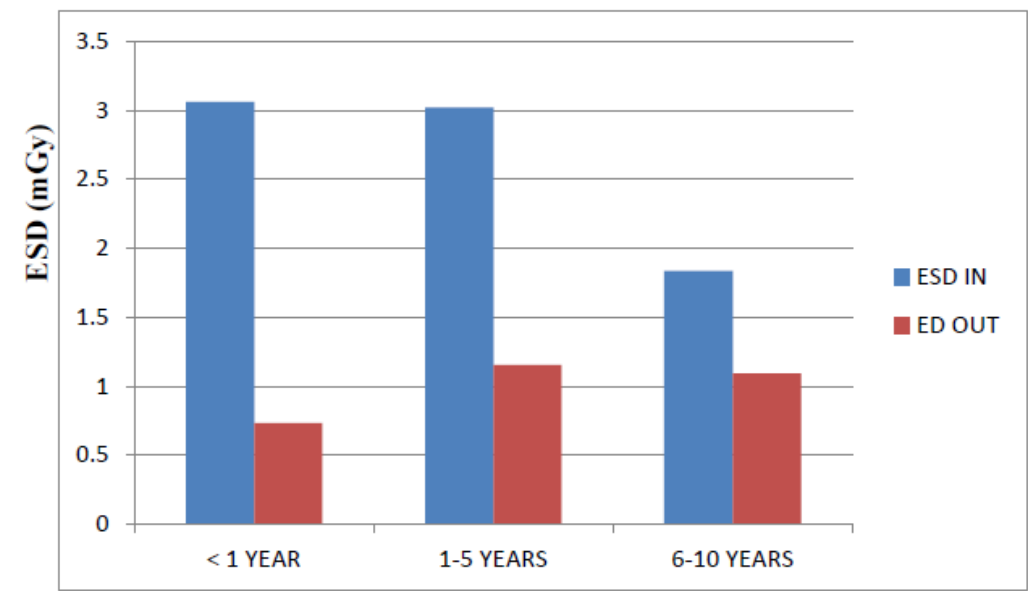

AGE (YEARS)

Figure 4. Measured Entrance Surface Doses and Exit Dose compared to each other

DISCUSSION

The result of this study shows that the Entrance Surface Dose (ESD) was higher than the normal values across the various age groups evaluated according to UNSCEAR. ${ }^{[3]}$ The normal values for (ESD) for < 1 year, 1-5 years and 6-10 years are: $0.02 \mathrm{mGy}, \quad 0.03 \mathrm{mGy}$ and $0.04 \mathrm{mGy}$ 
respectively. The higher values of ESD documented in this study is also in line with previous studies conducted by Egbe et al ${ }^{[8]}$, Ogundere et al ${ }^{[9]}$, Mooney and Thomas ${ }^{[10]}$ and Zewdu et $\mathrm{al}^{[11]}$ though with some discrepancies in their findings. Egbe et al ${ }^{[8]}$ in their studies, reported ESD from three different hospitals in Nigeria as follows: University of Calabar Teaching Hospital $(\mathrm{UCTH})$ as: $0.64 \pm 0.15 \mathrm{mGy}, 1.82 \pm$ $1.17 \mathrm{mGy}$, and $1.70 \pm 1.04 \mathrm{mGy}$ for $<1$ year, 1-5 years and 6-10 years respectively. For Federal Medical Centre Owerri (FMCO) as: $0.07 \pm 0.010 \mathrm{mGy}, 0.120 \pm 0.10 \mathrm{mGy}$ and $0.14 \pm 0.1 \mathrm{mGy}$ for $<1$ year, $1-5$ years and 6-10 years. For Nnamdi Azikiwe University Teaching Hospital (NAUTH): $1.10 \pm$ $0.10 \mathrm{mGy}, 1.040 \pm 0.30 \mathrm{mGy}$ and $1.10 \pm$ $0.1 \mathrm{mGy}$ for $<1$ year, $1-5$ years and 6-10 years respectively.

Ogundere et al ${ }^{[9]}$, reported (ESD) in their studies as follows: $0.350 \pm 0.150 \mathrm{mGy}$, $0.520 \pm 0.470 \mathrm{mGy}$ and $0.490 \pm 0.210 \mathrm{mGy}$ for < 1 year, $1-5$ years and 6-10 years respectively in the same hospital as above. Similarly, Mooney and Thomas ${ }^{[10]}$ also reported the ESD as: $0.060 \pm 0.020 \mathrm{mGy}$, $0.053 \pm 0.019 \mathrm{mGy}$, and $0.054 \pm 0.029 \mathrm{mGy}$ for $<1$ year, 1-5 years and 6-10 years respectively in Royal Best Hospital for Sick Children (RBHSC) Belfast, Northern Ireland. Although, all these findings are higher than the normal values documented by ${ }^{[4]}$, they are less than the values obtained in this study and this could be attributed to the sample sizes studied.

Our findings are in agreement with findings of the studies conducted by Egbe et $\mathrm{al}^{[8]}$, Ogundere et $\mathrm{al}^{[9]}$, Mooney and Thomas ${ }^{[10]}$, which were higher than the recommended values. This could be due to scatter contribution at the exit point, collimator scatter effects, and flattering filter scatter effect.

The result of this study on absorbed dose showed a higher value than normal, which was documented by NRPB-SR270 as $0.02 \mathrm{mGy}$ as cited by Hart et al. ${ }^{[7]}$ These high values are also in keeping with a previous study conducted by Okoye and
Avwiri. ${ }^{[12]}$ In this study, the values were higher than normal, but lower than the values obtained in this study across the various age groups evaluated. In Okoye and Avwiri ${ }^{[12]}$ study, the absorbed dose values are: $0.051 \pm 0.4 \mathrm{mGy}, 0.154 \pm 0.03 \mathrm{mGy}$ and $0.202 \pm 0.01 \mathrm{mGy}$ for $<1$ year, $1-5$ years and $6-10$ years respectively.

\section{CONCLUSION}

The values for exit dose (ED), entrance surface doses, (ESD) and absorbed dose (AD) have been determined and it was found to be slightly higher than the international recommended values. The peadiatric age related exit dose, entrance surface dose and absorbed dose have been established in our study, which could be use as a reference values in the locality of this study.

\section{Acknowledgement: None}

Conflict of Interest: None Declared

\section{Source of Funding: None}

\section{Ethical Approval: Approved}

\section{REFERENCES}

1. European Commission (EC). European guidelines on quality criteria for diagnostic radiographic images in paediatrics. Brussels: European Commision 1996.

2. International Commission of Radiation Protection. Radiological protection in paediatric diagnostic and international radiology. Draft Report for consultation ICRP Annals of the ICRP. ICRP publication 30, 2011.

3. Linet MS, Kim KP, Rajaraman . Children's exposure to diagnostic medical radiation and cancer risk: epidemiologic and dosimetric considerations Pediatr Radiol. 2009. Suppl 1(Suppl 1):S4-26. doi: 10.1007/s00247-008-1026-3.

4. UNSCEAR. Sources and effects of ionizing radiation. (Publication No. P1-76). Retrieved from http://www.unscear.org/docs/publications/2 000/UNSCEAR_2000_Annex-B.pdf.2000 
5. Elawed S O.A. Paediatric chest X-ray examination in general hospitals in Khartoum State (master's thesis). Sudan Academy of Science, Khartoum, Sudan 2011.

6. Wall, B. F. (1996). How to assess the dose to the patient in diagnostic radiology. USA: Charlie C.Thomas $9^{\text {th }}$ International Congress of international radiation protection Association R-02.

7. Hart D, Wall B F. Radiation exposure of the UK population from medical and dental Xray examinations. ( $2^{\text {nd }}$ ed.). [e-book]. 2001. Retrieved from http://www.hpa.org.uk/radiation/publication s/w_reports/2002nrpb_w4_htm.

8. Egbe N O, Inyang, S O, Eduwem D U, Ama I. Doses and images quality for chest radiograph in three Nigerian Hospitals. Journal of Radiography. 2009, (1): 30-36.

9. Ogundare F O, Ajibola C L, Balogun F A. Survey of radiological techniques and dose of children undergoing some X-ray examination three hospitals in Nigeria. Medical physics. 2004, 31 (3): 521-524.
10. Mooney R., Thomas P S. Dose reduction in a paediatric X-ray department following optimization of radiographic technique. The British Journal of Radiology, 1998; 71: 852860.

11. Zewdu M, Kadir E, Berhane M. Assessment of Pediatrics Radiation Dose from Routine X-Ray Examination at Jimma University Hospital, Southwest Ethiopia. Ethiop $J$ Health Sci. 2017;27(5):481-490. doi:10.4314/ejhs.v27i5.6

12. Okoye P C, Avwiri G O. Optimization of Absorbed Dose in Chest X-rays of Paediatric Patients at Braithwaite Memorial Specialist Hospital, Port Harcourt. Am. J. Sci. Ind. Res., 2013, 4(4): 349-358

How to cite this article: Emmanuel ZU, Ogolodom MP, Mbaba AN et.al. Survey of absorbed dose from chest X-ray of paediatric patients in Port Harcourt, Nigeria: a crosssectional study. International Journal of Science \& Healthcare Research. 2021; 6(4): 76-81. DOI: https://doi.org/10.52403/ijshr.20211012 